\title{
Alimentos, Reciprocidade e Fluxos: sobre a lógica da alternância nos Andes peruanos $^{1}$
}

\author{
Indira Viana Caballero ${ }^{2}$ \\ Museu Nacional/UFRJ, Rio de Janeiro, Brasil \\ E-mail: indiranahomi@yahoo.com.br
}




\section{Resumo}

Em Andamarca, a comensalidade e a produção de alimentos, desde a plantação até a confecção de pratos, tanto como dar e receber alimentos, são atos criadores de sociabilidade e reciprocidade entre diversos seres, humanos e não humanos. Recusar comida e bebida é algo que "no se pue$d e^{\prime \prime}$, sendo uma reação interpretada pelos andamarquinos como um ato de "desprecio", uma recusa à interação ou à possibilidade de criação de relação. Todos devem aceitar o oferecido e os alimentos devem ser oferecidos para todos, sem exceção, da mesma forma que as bebidas distribuídas nas festas. O objetivo deste trabalho é mostrar que esse movimento de inclusão do outro, que não deve desconsiderar ninguém, nos remete a outros movimentos de rotação/revezamento existentes em Andamarca, os quais privilegiam a circularidade dos fluxos e a alternância em detrimento da retenção/concentração.

Palavras-chave: Andes. Alimentos. Reciprocidade. Alternância.

\section{Abstract}

In Andamarca the comensality and the production of foods, spanning from cropping, the preparing of dishes, and the given and taken of foods are creative acts of sociability and reciprocity among several beings, humans and non-humans. Refuse food and beverages is something that it cannot be done ("no se puede"), an reaction interpreted by the Andamarquinos as an act of disdain ("desprecio"), as a refuse to interact or to the possibility of create relations. Everyone shall accept what is offered, and the foods, as well as the beverage distributed in the parties, must be offered to everybody without exception. The goal of this paper is demonstrate that the movement of inclusion of the other, which should not exclude nobody, remits us to other movements of rotation/alternation that exist in Andamarca, which privilege the circularity of flows, the alternance over the retention/concentration.

Keywords: Andeans. Foods. Reciprocity. Alternation. 


\section{Introdução}

ndamarca é um pueblo situado na província de Lucanas, departa-
mento de Ayacucho (Peru), Valle de Sondondo 3 , muito conhecido por seu preservado sistema de andenería, o qual é constituído por plataformas agrícolas escalonadas - chamadas também de andenes - dispostas ao longo de uma ampla variedade de microclimas entre 3.000 e 4.000 metros de altitude ${ }^{4}$. Andamarca é o nome do pueblo matriz ou capital do distrito de Carmen Salcedo ${ }^{5}$, cuja população é de aproximadamente 2.500 habitantes. Além da sede, o distrito possui três anexos ou pequenas vilas: Chiricre, Huaccaracca e Huayllahuarmi ${ }^{6}$.

Cortada pelo rio Negromayo, Andamarca tem seu vale dividido em duas margens: oriental, alimentada pelo rio Vizca; e ocidental, alimentada pelo rio Negromayo. O curso deste rio, segundo ressaltou Juan Ossio (1992), é muito importante para os andamarquinos, pois sua direção é usada pelos moradores para classificar territórios de acordo com o clássico padrão andino alto e baixo (hanan e uray). Como esse rio origina-se em território andamarquino, os moradores consideram sua comunidade mais alta que outras situadas ao longo da bacia como um todo. Assim, referem-se aos outros pueblos do Valle de Sondondo como "pueblos de más abajo", cuja direção está sempre ao norte de Andamarca ${ }^{7}$.

O pueblo encontra-se na margem ocidental, enquanto os três anexos estão na margem oriental, o que foi interpretado por Ossio como uma tentativa de simetrização das duas margens. O autor enfatiza um aspecto que, em sua percepção, destaca tal tentativa: cada um dos anexos está situado num dos três principais níveis ecológicos para os andamarquinos. Chiricre, o de maior tamanho, fica no vale, quase 
em frente ao pueblo; Huaccaracca, o segundo maior, está entre a puna (altiplano) e o vale; e Huayllahuarmi é um conjunto de "estancias" na puna. (Ossio, 1992, p. 51)

Em 1944, Andamarca emancipou-se de Cabana, povoado vizinho muito antigo do qual fazia parte como um de seus anexos. Entretanto, nem sempre a relação entre os dois pueblos teria sido exatamente essa. Juan Ossio (1981) afirma haver evidências históricas de que Cabana, Andamarca, Huaycahuacho e Sondondo, outros dois pueblos da região, formaram o Ayllu Antamarca antes das reduções do Vice-rei Francisco de Toledo em 1580. Cabe destacar que ayllu é o conceito que designa a todo grupo social, seja ele baseado no parentesco, na localidade, em critérios cerimoniais, etc. (Ossio, 1992, p. 194). Conforme Ossio (2008), os cronistas Guamán Poma e Luiz de Monzón mencionam que o Repartimiento de los Rucanas Antamarcas esteve integrado por quatro ayllus que foram reduzidos a pueblos, e ambos os cronistas coincidem na ordem da sequência: Antamarca, Apcara, Omapacha e Uchuc Ayllu. Por ser o primeiro e ter dado nome a todo o repartimento, entende-se que Antamarca era o mais importante dos quatro (Ossio, 2008). O autor afirma, ainda, que o Ayllu Antamarca desmembrou-se em Cabana e outros dois pueblos, os quais se transformaram em seus anexos: Huaycahuacho e Sondondo.

O princípio da origem quadripartite dos ayllus e dos pueblos está presente também no mito que narra a origem de Andamarca (Ossio, 1992), intitulado "Os quatro irmãos Mayo", o qual apresenta grande semelhança com o mito da origem de Cuzco, cujos personagens centrais são os quatro irmãos Ayar. Nessa narrativa, destaca-se também a importância da água na origem de Andamarca, já que mayo significa rio.

Conforme Ortiz (1980, p. 54-55), os números quatro e dois são muito significativos na realidade andina:

[...] ao mundo do Presente também se lhe chamou Tawantinsuyo [como o Império inca] e quase todas as comunidades andinas estão dividas em duas partes (alto e baixo), e por sua vez em quatro partes ou "bairros" antagônicos, rivais e ao mesmo tempo complementários.

Seguem na mesma direção os comentários de Ossio em seu artigo "Andinidad" (2007), onde retoma as crônicas do século XVII de "Los 
Comentarios Reales del Inca Garcilaso de la Vega" para argumentar a importância que a divisão em metades apresenta desde os tempos da fundação da cidade imperial de Cuzco. Para o autor, esse padrão de dividir as cidades em metades, no caso de Cuzco Hanan Cozco (Cuzco Alto) e Hurin Cozco (Cuzco Baixo), é visto ainda hoje entre comunidades andinas estando relacionado ao princípio da reciprocidade. Dessa forma, o corpo social é dividido em metades essencialmente complementares. (Ossio, 2007, p. 46)

Segundo moradores de Andamarca, desde o "tiempo de los abuelos", o pueblo estava dividido em dois bairros principais: Pata (oriente) e Tuna (ocidente), tal como as partes de um andén: pata é a borda, a parte da frente; e tuna, também chamada de canto, é a parte posterior. Segundo Juan Ossio (1992), os nomes dos bairros ressaltam a grande importância que os andamarquinos concedem às andenerías, a ponto de conceber a seu pueblo como um enorme andén. A divisão em metades é algo recorrente em vários pueblos andinos e uma das expressões máximas da organização dualista - ver Ortiz (1980) e Ossio (1992). Posteriormente, cada bairro foi divido em outros dois: Ccarmencca (sul) e Antara (norte), formando assim quatro partes, os quatro bairros de Andamarca. A Rua Jirón Lima, onde se concentra o comércio local, corta o pueblo de sul a norte, ressaltando a fronteira entre Tuna e Pata. Essa rua também é chamada pelos andamarquinos de Chaupi Calle, ou rua central, pois chaupi significa centro, meio, metade?

A importância da divisão em partes ou bairros está relacionada à capacidade de organização dos andamarquinos para diferentes fins. Cada bairro possui um presidente acompanhado de um comitê (junta directiva). Se houver uma faena por bairro, um dia de prestação de trabalho gratuito à comunidade, por exemplo, eles são os responsáveis por sua organização, ou seja, por recrutar, organizar, fiscalizar e sancionar os membros que não cumprirem com suas obrigações. Diversas atividades coletivas são organizadas por bairros, inclusive protestos e programas sociais.

Dessa forma, a divisão em partes engendra uma competição positiva, um princípio caro para os andamarquinos, como mostra o mito que Juan Ossio (2007) extrai do estudo de Salvador Palomino (1984) 
sobre a comunidade de Sarhua, revelando o que o autor caracteriza como um traço das cosmologias andinas. Quando todos eram iguais e não existiam ayllus, não havia "ânimo" para trabalhar. Até que os homens pensaram em se opor uns aos outros, e a autoridade os dividiu. Com a divisão foi introduzido um "[...] estímulo para o trabalho, pois permitiu a competição, que uns rivalizassem com os outros e que se acelerasse o trabalho". (Ossio, 2007, p.47). As oposições, assim, colocam-se em função de uma dinâmica que estimula o ânimo entre os homens para que as tarefas sejam efetuadas com certo prazer. Com isso, os andamarquinos diminuem o peso e a lentidão na execução de grandes obras e atividades, fazendo com que elas se assemelhem e se confundam com as próprias festividades.

\section{Trabalho Agrícola e Outras Atividades}

Os andamarquinos costumam dizer que Andamarca é um "pueblo campesino", considerando-se a si próprios "campesinos". Com raras exceções, todos se dedicam à agricultura e à pecuária, pois todos possuem ao menos uma pequena área de terra e/ou um animal. Entretanto, os andamarquinos ressaltam que a agricultura é destinada para "consumo" próprio, e não para "mercado", como fazem os moradores de outros pueblos andinos que vendem seus produtos em feiras, fazendo dessa atividade sua principal fonte de ingressos. O produto confeccionado pelos andamarquinos para ser comercializado é o queijo, como veremos adiante. Ainda assim, a venda de pequenas quantidades de produtos agrícolas (batatas e milho, principalmente) entre os próprios andamarquinos é uma prática corrente. Há também alguns ganaderos, assim chamados os que se dedicam à compra e venda de gado. Essa é uma atividade mais lucrativa, que requer mais despesas, porém proporciona maiores rendimentos e, consequentemente, maior possibilidade de acumulação de dinheiro e de bens.

Depois das tarefas relacionadas ao campo, o comércio aparece imediatamente como atividade mais praticada. Talvez por oferecer flexibilidade para cuidar das chácaras e animais de dia, e de vender à noite. A maioria dos estabelecimentos comerciais funciona a partir do final da tarde, horário em que todos já voltaram do campo ou estão 
voltando. Um considerável número de armazéns está espalhado pelo povoado; a maioria deles comercializa apenas artigos de primeira necessidade (pão, azeite, sal, açúcar, fósforos, arroz, massa, sabão, papel higiênico), e poucos oferecem mercadorias sortidas e novidades (roupas, sapatos, doces, enlatados variados, carnes, material escolar, etc.), atraindo, por conta disso, maior clientela. A quantidade, qualidade e diversidade das mercadorias revelam muito sobre a prosperidade e o êxito de cada negociante.

Nos últimos anos surgiram hospedarias e restaurantes, ambos voltados para o desenvolvimento do turismo local, sobretudo aquele chamado de "vivencial" ou "comunitário", muito difundido no Peru, cujo objetivo é fazer com que o visitante vivencie o dia a dia local, ainda que por poucas horas - ver Alfaro Freire (2011). Sob essa perspectiva, celebrações locais, tarefas cotidianas e recursos naturais vão sendo apresentados para fora do pueblo como atrativos turísticos. Assim, os andamarquinos buscam nessas e em outras atividades mais recentes - como a criação de abelhas e peixes, ainda bem menos frequentes novas possibilidades de ganhos em seu próprio pueblo. Dessa forma, não será necessário deslocarem-se para as cidades da costa à procura de trabalho, principal causa da migração dos jovens nos últimos anos.

As terras de Andamarca são divididas em comunais e privadas. As primeiras são de propriedade da comunidade, são terras coletivas das quais todos os comuneros podem usufruir. A administração dessas terras está a cargo da Directiva Comunal, instituição tradicional totalmente independente da Prefeitura (Municipalidad), cuja autoridade máxima é o presidente da comunidade, que conta com uma junta directiva (vice-presidente, secretário, tesoureiro, fiscal e suplente), todos eleitos em assembleia geral bienal.

Os pastos comunais na puna (altiplano) são destinados fundamentalmente à pecuária, incluindo a criação de camelídeos (lhamas e alpacas), ovinos e bovinos. Estão divididos em dezoito setores, cada um com seu presidente e sua junta directiva, eleitos a cada dois anos pelos usuários de cada setor. Todo comunero que desejar usufruir das terras na puna deve consultar a associação do setor, a qual decidirá junto aos usuários sobre o seu direito, havendo uma tendência de que membros da mesma família ocupem o mesmo setor. 
As terras privadas são as chácaras, ou andenes, localizadas no vale, onde se concentra toda a atividade agrícola de Andamarca. Estão divididas em dezoito setores para fins de irrigação, cada um com seu yaku alcalde, ou prefeito de águas, as autoridades encarregadas especificamente de distribuir a água e ordenar a irrigação, além de um presidente e uma junta directiva. A Comisión de Regantes é a instituição legítima para fiscalizar, punir e tratar de diferentes questões ligadas ao uso da água em todo o território andamarquino, sendo seu presidente eleito a cada três anos, com um comitê. A irrigação tem dia e hora para começar, bem como uma ordem específica, sendo que cada comunero deve observar algumas regras para exercer seu direito de uso da água, e pagar uma taxa se o cultivo for para negócio - no caso da criação de vacas leiteiras para a confecção e venda de queijos - e não para consumo próprio.

Se as atividades agrícolas estão concentradas no vale, a pecuária é praticada tanto no vale como na puna. No entanto, é preciso considerar a diferenciação que os andamarquinos fazem entre as vacas do altiplano e as das chácaras. As vacas criadas nos pastos das alturas são predominantemente chuscas, o que pode ser traduzido por nativo, ou que não é de raça, vivendo soltas, sem cuidados diários. Esses animais são descritos pelos andamarquinos como selvagens, chúcaros (chucros), bravos, ariscos. Parte dessas podem ser "vacas urwa", estéreis, "que comem grátis", dizem os andamarquinos, pois não dão leite. O gado da puna geralmente constitui rebanhos grandes, compostos por dezenas de animais, em contraste com a pecuária praticada no vale, cujo número de animais dificilmente ultrapassa a dezena. Embora sejam animais menos valorizados, ainda assim eles são uma espécie de poupança para seus proprietários, necessitando de poucos cuidados e investimentos, diferentemente dos animais das chácaras.

As vacas criadas nas chácaras são leiteiras, ou chauana (do verbo quechua chauar, ou ordenhar), e podem ser chuscas ou mejoradas (vacas de raça, mas não puras), o que as diferencia não apenas pela quantidade de leite que produzem, mas também pelo tamanho, peso, pelagem, características muito prezadas pelos andamarquinos. As vacas leiteiras são muito estimadas e valorizadas também por causa 
de seu potencial gerador de economia (dinheiro). A base da alimentação desses animais é a alfafa, e por essa razão muitos andenes antes destinados à plantação de milho passaram a ser destinados apenas à plantação dessa forragem. É necessário ressaltar que esse é o único meio de se ganhar algum dinheiro com as chácaras, arrendando os alfalfares, pois como a venda de queijos nos mercados em Lima é a principal fonte de renda da maioria das famílias, todos precisam manter seus animais bem alimentados.

A maioria dos andamarquinos diz que planta "por costume", referindo-se às atividades agrícolas nos dias de hoje como algo que "no te sale [la cuenta]", ou seja, que não há equivalência entre os investimentos financeiros requeridos para plantar e os produtos agrícolas colhidos, o que pode ser entendido como prejuízo, embora eles nunca utilizem tal palavra. Apesar dos grandes esforços e investimentos necessários, plantar é a garantia de manter uma determinada dieta e de conservar as chácaras produtivas, impedindo que os terrenos sejam tomados por espinhos (cactos) e ervas daninhas. Uma chácara abandonada perde grande parte de seu valor, sendo necessário mais tarde muito trabalho para recuperá-la. Mas a agricultura aciona ainda outros valores, como veremos adiante.

Andamarquinos que dispõem de pastos comunais exercem atividades tanto na puna como no vale, sendo que as famílias (marido, esposa e filhos) reúnem-se na puna, sobretudo, na estação chuvosa (entre dezembro e março), a qual coincide com as férias escolares. No restante do ano, mulheres e crianças permanecem no pueblo mantendo a rotina; as mulheres devem cuidar da casa, dos filhos e das vacas, estando encarregadas também de enviar víveres para seus maridos periodicamente. Por conta disso, a puna é descrita por alguns como um lugar "triste", pois solitário, vazio; imensidões de pastos onde predominam homens sozinhos com seus animais.

Apesar de praticarem o pastoreio, os andamarquinos caracterizam-se por serem exímios agricultores, conhecimento que amiúde ressaltam como uma herança de seus ancestrais pré-hispânicos, enfatizando o trabalho como forte valor. Diante de suas narrativas, encontramos em oposição os "sallqas", "povo da altura", pastores 
habitantes permanentes da puna localizada em outros municípios. Sallqa é um termo com conotação pejorativa que significa "selvagem", "eremita", "índio", sendo também um sinônimo de puna. Essa noção da puna ou sallqa como um espaço com caráter selvagem em oposição ao civilizado, o qual estaria associado ao vale, aparece em Isbell (2005) e Ossio (1992). Assim, chamados pelos andamarquinos pelo mesmo nome que se dá a esse piso ecológico, os sallqas seriam outro tipo de gente, pertencentes a outra natureza. Nascem na puna, vivem na puna e não se dedicam à agricultura, o que para os andamarquinos os define como não trabalhadores: "Não sabem trabalhar, não sabem plantar". São qualificados de qillas, palavra quechua que significa preguiçoso, por se dedicarem ao pastoreio, atividade que não demandaria o mesmo esforço físico e perícia que a agricultura: "Passam o dia todo sentados, apenas olhando seus animais".

Por causa dessa insuficiência produtiva é que os andamarquinos buscam enfatizar negativamente, esses pastores da puna são muito conhecidos pelos longos deslocamentos que fazem do altiplano em direção à costa com o objetivo de trocar seus únicos produtos (charque e utensílios tecidos como huaracas, fundas), por tubérculos, cereais, grãos, legumes, frutas, enfim, os produtos característicos dos lugares pelos quais vão passando. Nesses longos trajetos percorridos a pé, os pastores andam acompanhados por dezenas de lhamas, geralmente adornadas, as quais carregam inúmeros artigos, uma cena cada vez menos comum nos dias de hoje.

Então é interessante ressaltar três pontos: (i) desde o ponto de vista andamarquino, as pessoas originárias dessa zona, os sallqas, têm as mesmas características atribuídas ao lugar; (ii) o trabalho, desde os tempos dos Incas, recebe grande ênfase como um valor moral, estando entre as três "leis dos Incas": ama suwa (não seja ladrão), ama qilla (não seja preguiçoso), ama llulla (não seja mentiroso); finalmente, (iii) para os andamarquinos o trabalho por excelência é o trabalho agrícola.

No entanto, de acordo com minha experiência em campo, podese dizer que as atividades que demandam considerável esforço físico, em geral, são vistas como trabalho pelos andamarquinos. A criação de vacas leiteiras é uma delas, posto que também requer grande investi- 
mento de tempo, dinheiro e esforço físico, sendo por vezes comparada à "escravidão": "Quem tem vacas não tem feriado". O valor do trabalho se expressa por sua negativa, sendo o preguiçoso uma figura muito negativa. Ao contrário daquele que trabalha com sacrifício: “Quem se sacrifica tem para comer, tem suas terras, seus animais. Aquele que não tem é porque é preguiçoso".

\section{Sobre os Alimentos: produção e consumo}

Diferentes tipos de batatas cozidas "con su quesito", choclo (milho verde), mote (milho debulhado cozido), sopas e picantes (refogados) de quinoa, batata e olluco fazem parte da alimentação diária dos andamarquinos, a qual é composta geralmente por três refeições no decorrer do dia. No almoço e no jantar, uma refeição completa inclui "la sopa, su segundo y su aguita", (uma sopa, o prato principal e um chá), porém, nem sempre é possível fazer uma em meio a tantas tarefas do dia a dia. Por uma questão de tempo e praticidade, os andamarquinos acabam recorrendo com frequência ao duo batata com queijo, ou milho com queijo, uma refeição prática e leve, usualmente levada para a chácara.

Pela manhã, a preferência dos andamarquinos é por uma porção razoável de comida substanciosa para que a pessoa possa "aguentar" o trabalho duro no campo. Para que se tenha força, o corpo não deve ser constituído predominantemente por "comida de tienda" (comida de armazém), ou seja, comida industrializada, como massas e pães. Isso ficava explícito durante as tarefas na chácara quando os andamarquinos comparavam meu corpo ao deles, salientando minha falta de força para o trabalho braçal: "Si comes fideos nomás... Hay que comer papa, maiz...". Ou seja, "lo que es de la sierra", "lo autóctono", em quantidades consideráveis. Mesmo sabendo que minha alimentação não era composta apenas por massa, também sabem que as pessoas da cidade costumam comer outros alimentos pela manhã (iogurte, leite, suco, pães, geleias, sanduíche). Entretanto, ressaltam que esse tipo de alimento não é suficiente para aquele que trabalha, "con eso no se aguanta".

Aparece, portanto, a oposição comida de tienda e comida autóctone (ou "natural", "de los abuelos"), contraste que se destaca com o crescimento de programas sociais como "Vaso de Leche" - que distribui latas 
de leite para famílias consideradas pobres - e o aumento da comercialização de produtos industriais nas áreas rurais (sobretudo açúcar, azeite, arroz, massas, pães e bolos, leite enlatado). A categoria "de tienda" remete à costa, lugar onde "todo es plata", pois mais urbano sendo cidades e não pueblos, o que no Peru significa "rural" -lugar de origem dos produtos citados acima. Dessa forma, ao serem empregadas tais categorias são acessados seus significados. Nas narrativas dos andamarquinos, a costa/cidade aparece sempre associada à noção de poluição. Um contraste em comparação com Andamarca, lugar com "ar puro", "céu azul", onde a comida é "natural", "saudável" ("sana"). Embora os andamarquinos consumam produtos industrializados, com frequência costumam marcar essa oposição entre as duas regiões.

A oposição costa/sierra é muito significativa, perpassando várias dimensões, e não apenas essa relacionada à alimentação. Faz-se necessário mencionar que no passado recente de Andamarca, essa é uma questão evidente quando se trata dos "mistis". A palavra quechua misti deriva de mestiço, forasteiros que chegaram a Andamarca no final do século XIX, graças à resistência da população local, enquanto nos arredores eles se fixaram mais cedo. Desde a perspectiva dos andamarquinos, que nesse contexto se autodefinem como "indígenas", "autóctones", os mistis tinham a pele mais branca, sabiam ler e escrever, falavam espanhol apesar de muitos dominarem o quechua, tinham sobrenome espanhol, usavam roupas com estética urbana, faziam uso da força sobre os indígenas - o que faz com que sejam descritos sempre como "abusivos" $-{ }^{10}$, e dedicavam-se principalmente ao comércio e à compra e venda de gado.

Para os andamarquinos, todos os alimentos são divididos em duas categorias: frios e quentes. O que faz precisamente que um alimento pertença a uma ou a outra categoria é algo que, de fato, ainda não compreendo inteiramente. Um amigo me dizia que as comidas frias são aquelas que fazem a barriga "reclamar" imediatamente, emitindo ruídos. O mote, por exemplo, é frio, e a batata é quente. O corpo precisa de um consumo equilibrado de alimentos de ambos os tipos, caso contrário o excesso de um ou de outro pode causar "enfermedades" e "males" em geral, que podem ser sanados com a neutralização do 
excesso. Isso pode ser alcançado com a ingestão de bebidas quentes como os emolientes.

Determinados alimentos, enfatizam os andamarquinos, devem ser ingeridos quentes, como a sopa e o charque. Consumir um dos dois no campo, por exemplo, onde pode ventar muito, não é bom, pois esfria rápido. Para os andamarquinos, a origem de muitos males e doenças pode estar associada ao excesso de frio ou de calor - seja relacionado aos alimentos ou ao próprio clima-, ou pode estar também associada ao "daño" feito por seres como a pachamama (mãe terra), os apus (montanhas protetoras), os ancestros ou abuelitos (antepassados). Geralmente, o daño manifesta-se na forma de uma doença estranha ou algum mal não tratável e/ou não curável pela medicina ocidental convencional. Embora esse seja um tema de grande relevância, não será aprofundado aqui.

Neste texto, ressalta-se que, da plantação de produtos agrícolas à confecção de pratos, duas instâncias distintas de produção de alimentos e, evidentemente, seu consumo, são atos criadores de sociabilidade e reciprocidade entre diversos seres, humanos e não humanos, em Andamarca. O que está em jogo nesses momentos, em grande medida, é a valorização da reciprocidade e o compartilhamento de substâncias, assim como certa disposição dos andamarquinos para incluírem o "outro".

O ciclo agrícola é iniciado depois da Festa da Água, que ocorre no final de agosto; e a plantação propriamente acontece dias depois da irrigação das chácaras. A irrigação é feita sempre de baixo para cima; os andenes mais abaixo são os primeiros a serem regados, e os mais acima são os últimos, evitando-se desmoronamentos. Dentro da chácara, o objetivo é fazer a água circular, já que a retenção da água e inundação em demasia do terreno pode ocasionar estragos, causando a queda do andén. O controle e a distribuição da água são feitos com o auxílio de divisões, caminhos desenhados na terra chamados de "eqas" (quechua) ou "bordes" (espanhol). Para regular o volume de água que entra no andén são usadas pedras, esterco, terra e plantas. A pessoa que rega deve buscar uma distribuição equânime da água, que alcance todas as partes do andén: as extremidades e o meio. Para tanto, 
"é preciso conduzir a água", ir traçando com uma ferramenta outros pequenos caminhos. Ao terminar, deve-se "fechar a água" usando pedras, esterco e plantas conforme a intensidade da água, para que a água "respeite as eqas".

Diferentemente da irrigação, feita por uma ou duas pessoas, a semeadura é uma atividade coletiva. A tarefa de separar as sementes, abrir sulcos com arado de touros e depositar sementes possui um tom festivo, sobretudo se o produto plantado for o milho, ocasião em que se faz "Pito", denominação corriqueira para a comemoração familiar que acontece nas chácaras. Pito, na verdade, é o nome da bebida que se prepara especialmente para essa celebração. De consistência pastosa, o pito resulta da mescla de chicha de qora, bebida fermentada de milho, com machka, uma farinha fina de cereais variados, com um pouco de açúcar e canela, muito apreciado pelos andamarquinos.

Todos estão virtualmente convidados para o Pito: alguém que porventura esteja passando por perto, um vizinho de chácara ou de casa, um parente distante, um conhecido, um visitante; enfim, qualquer pessoa que queira chegar será recebida da mesma forma, com comida e bebida - sendo um procedimento adotado pelos anfitrióes em todas as festas em Andamarca. Segundo a etiqueta local, cabe ao visitante levar uma garrafa de "vinito", ou outro tipo de bebida alcoólica, além de um par de flores grandes de cores vibrantes para oferecer ao casal dono da chácara, que devem usá-las em seu chapéu, tanto o homem como a mulher, sinalizando a ocasião festiva. Caso a pessoa seja surpreendida por um convite e não disponha de nenhum dos dois artigos para oferecer no momento, será ainda assim recebida da mesma forma. Mesmo constrangido, o convidado deverá aceitar tudo que lhe derem de comer e de beber, deixando para retribuir posteriormente.

O Pito, ou Pata Tarpuy Raymi, a Festa da Semeadura, está tornando-se cada vez menos frequente por ser "muy trabajosito" e por demandar "mucho gasto". Além da comida e bebida que devem ser ofertadas, atualmente é preciso pagar ao arador e à semillera, mulher encarregada de depositar as sementes (geralmente a esposa do arador), personagens indispensáveis ao ritual e que, antigamente, não recebiam dinheiro. Os andamarquinos costumam dizer que "antes tudo 
era ayni", isto é, prestação de trabalho recíproco. No passado, amigos e parentes participavam dos afazeres no campo apoiando-se uns aos outros mutuamente, diferentemente dos tempos atuais em que todos querem receber um pagamento em dinheiro. Outro fator que contribui para essa mudança é a diminuição do número de membros das famílias que podem cooperar. Esse é um importante efeito dos deslocamentos dos andamarquinos para a costa, e até mesmo para outros países. Nesse processo, nota-se que a população jovem é a que se desloca com maior frequência, permanecendo no pueblo adultos e idosos, cuja força de trabalho vai enfraquecendo com o passar dos anos.

Participar da plantação de batatas na chácara de um casal de amigos em 2010, senhora Irene e senhor Celso (ambos com pouco mais de 60 anos), cujos filhos vivem todos na Argentina, foi uma experiência crucial para aprender sobre as atividades no campo e, indubitavelmente, para estreitar laços com essa família. Nesse dia extraordinário, afinal espera-se aproximadamente por um ano para que esse momento se repita, passei na casa do casal para irmos todos juntos à chácara. Enquanto os homens carregavam os burros com ferramentas, sacos de sementes, chicha de qora, senhora Irene e a mulher do arador encarregavam-se da comida. No trajeto, senhor Celso e o arador conduziam os burros e os touros, e as mulheres carregavam nas costas mantas volumosas e pesadas com a comida e os utensílios para a refeição (copos de vidro, canecas, pratos e talheres de sobremesa, menores e mais leves). Em ocasiões especiais como essa, a comida é levada pronta em uma panela bem envolvida por uma manta para permanecer quente por mais tempo. Quando chegamos ao destino final já havia um vizinho dos "donos" (da chácara) trabalhando. Mesmo de muletas, o senhor trabalhava sentado no chão separando sementes juntamente com a mãe da senhora Irene, uma anciã de mais de 80 anos.

As sementes de batata eram principalmente de cinco tipos: blanca, amarilla, roja, huayro e ceqcha. Um pouco antes de começarmos, senhora Irene ofereceu chicha a todos e antes de beber cada um aspergiu em cima de cada tipo de semente, "para que elas cresçam", disseram-me. Também havia vinho para fazer libações ou "tinkar", brindar, oferecer à pachamama, apus e antepassados, para que tudo "te vaya bien" durante a semeadura. Pouco depois começamos o trabalho, 
as mulheres depositando as sementes e os homens assumindo o papel de aradores, uma tarefa considerada por todos "pesada", que requer muita força física e, segundo as mulheres, uma das únicas atividades na qual os homens "nos ganham" - o que significa ser das poucas tarefas que elas não conseguem executar. Eu fazia parte da equipe das semilleras, pois quando o terreno é grande é preciso haver várias mulheres para depositar as sementes nos sulcos que se abrem com o arado. "A cada passo, coloca duas ou três, dependendo do tamanho", assim me ensinaram as mulheres. Cada uma de nós estava responsável por um trecho do sulco, enquanto um homem guiava os touros e o outro empurrava o arado. Quando o estoque de sementes terminava, era preciso reabastecer nossas mantas rapidamente, de preferência uma de cada vez, de modo que o trabalho não fosse totalmente interrompido. Para que a atividade seja executada com sucesso, aprendi na prática que se trata de um trabalho cujo ritmo é bem marcado, demandando sincronia e agilidade da equipe, sendo fundamental que o apoio entre os participantes seja recíproco. Caso contrário, o trabalho "não avança", o que não é desejável, pois há uma porção de preparativos e cálculos para a execução das tarefas no campo.

No final do dia, pouco antes de começarmos a recolher os objetos para ir embora, fui surpreendida por senhora Irene: "Mami ${ }^{11}$, vou te dar dois sulcos de batatas, para ti, nada mais. Assim vai ter tua comida e também vai economizar dinheiro...". "Para mim? Mas eu nem tenho onde cozinhar...". "Pede pra outros amigos que cozinhem pra ti", e nomeou alguns. Sem ter como recusar, agradeci por sua preocupação: “Obrigada, senhora Irene, muito obrigada! Ano que vem virei especialmente para colher minhas batatas". E assim o fiz. As duas linhas de batata eram uma retribuição pelo meu esforço em depositar as sementes. Mais tarde, descobri que antigamente, quando as famílias tinham vários andenes, essa era uma prática muito comum entre parentes próximos, principalmente filhos, noras e "filhos de juramento"12. Quando se dá parte do que foi plantado à outra pessoa, essa deve retribuir com "su gaseosita" (refrigerante), ou algo do tipo, o que fiz alguns dias depois. Também pode ser uma quantia em dinheiro para ajudar na manutenção das chácaras até a colheita. Segundo 
alguns amigos, essa prática de dar cultivos no momento da plantação tornou-se menos habitual com o passar dos anos porque com a divisão por herança, o tamanho das chácaras foi diminuindo, e quando se dá a outros a colheita "já quase não alcança" para a família (casal e filhos).

Possuir um pequeno estoque de batatas significava a possibilidade de trocar, de presentear e, evidentemente, de comer. A produção de batatas, assim como a de milho, garante às famílias a manutenção de certo modo de vida, mais próximo do que se entende como rural ou campesino, além de reduzir os gastos com comida de tienda. Dispor de consideráveis quantidades desse tubérculo significa ter comida garantida por algum tempo, poder celebrar festas (muitos pratos locais são feitos com batatas: sopas, picantes, carapulcra etc.), fazer trocas por outros mantimentos com parentes e amigos, e até ganhar dinheiro com a venda de uma parte do estoque (cruas ou transformadas em diferentes pratos). Em suma, significa manter relativa autonomia.

Para que os produtos agrícolas sejam devidamente armazenados, depois da colheita eles precisam ser sistematicamente classificados, tarefa trabalhosa que requer muita "paciência". As principais categorias são: "bonitas", "feias" ("con su cascarita pelada", faltando pedaços), "pequenas", "grandes", "uru" (gusano) ou "con gusanos" (com larvas). Conforme suas características físicas são destinadas para um fim. Sra. Irene ficava com dó cada vez que via alguma batata machucada, sem um pedaço da casca: "Pobrecitas mis papas", dizia. "Olha... Como haverão chorado minhas batatas...". Um dos três burros que carregava os sacos da colheita atirou no chão o saco cheio de batatas e depois passou por cima. Segundo ela, suas batatas choraram "por culpa do burro malcriado", acrescentando que o animal está muito mal acostumado, convencido, confiante ("sobrado"), porque está comendo muito bem. Essa passagem nos remete às referências de Arnold e Yapita (1998) sobre a capacidade de chorar dos produtos, tanto como os humanos, quando nascem e em qualquer outro momento se não forem bem cuidados. Os autores falam sobre uma "metafísica da batata", pois segundo "[...] as idéias aymaras, a batata não é simplesmente uma comida inanimada, senão que, como todas as coisas do universo andino, tem vida". (Arnold; Yapita, 1996, p. 140) 
Devidamente selecionados, os produtos agrícolas são finalmente transformados em diferentes pratos. Por diversas vezes, auxiliei a senhora Irene na cozinha, geralmente descascando e cortando alimentos. Esses são momentos em que se compartilham conhecimentos e substâncias, também como uma contrapartida pela ajuda. Quando se tratava da comida que senhora Irene fazia para vender, sempre ganhava um desconto ou um "aumento" (yapa ou llapa), um "choro" (para usar uma gíria em português), no ato da compra.

A comensalidade, portanto, surge em Andamarca como um momento criador de sociabilidade e intercâmbio, tanto no compartilhamento repetido e recíproco do cotidiano como durante as festas, momentos extraordinários de grande importância no que se refere à construção de laços e ao aprofundamento de vínculos (Belaunde, 2001; Coconier, 2012; Overing, 1999). Nessas ocasiões as refeições servidas aos convidados são sempre completas (sopa y segundo), estando entre as preferências dos andamarquinos as sopas de mote e os picantes de papas. Diferentemente da comensalidade diária, os momentos festivos são mais formais. Deve-se aceitar o oferecido de qualquer forma; caso não seja do desejo do convidado consumir imediatamente, pode solicitar "bolsita" plástica, uma novidade nas festas em Andamarca, que permite levar a porção a que se tem direito para casa. O convidado pode também levar seu próprio recipiente de casa, sinalizando aos anfitriões que não têm a intenção de recusar o que é oferecido, apenas não pode consumi-lo naquele momento. Nesse caso, a pessoa deve ter alguma razão (uma doença, um mal-estar físico, ou haver recebido o convite imediatamente após uma refeição) que justifique sua exclusão do momento em que todos estarão comendo juntos. Não se pode simplesmente recusar o oferecido, sendo de grande importância "receber" o que é dado ("hay que recibir"). Os andamarquinos jamais recusam comida entre eles, e os forasteiros tampouco devem fazê-lo.

Na compreensão dos andamarquinos, a recusa de comida e bebida é claramente um sinônimo de "desprecio", uma recusa à interação, à possibilidade de retribuição, à possibilidade de criação de relação. Em oposição, o ato de oferecer é visto como um gesto de "carinho". Portanto, se "no se puede" recusar, tampouco se pode deixar de oferecer, ou convidar. Toda pessoa presente deve ser convidada para comer e 
para beber. Nas festas, momentos em que se formam enormes rodas ou "redondelas", com dezenas de participantes que dançam intensamente variações de sapateados andinos, a bebida deve passar por todos, devendo fazer "la vuelta" e "no saltar" ninguém. Da mesma forma que um anfitrião pode zangar-se com alguém que recusa sua comida, também pode incomodar-se com os convidados que não dançam e, assim, dizer que está gastando seu dinheiro em vão (no pagamento dos músicos). As festas são celebradas para que os convidados comam, bebam e dancem, sendo a oportunidade que o anfitrião tem de proporcionar comida, bebida e música para todos. Muitas vezes, é preciso economizar durante anos até que seja possível oferecer uma festa, seja ela prevista no sistema de cargos, seja um casamento, batizado ou outro. Esse é mais um fator que pode fazer com que a recusa do que é oferecido seja interpretada de forma tão ofensiva pelos andamarquinos.

\section{Sobre o Ato de Compartilhar}

Em Andamarca ainda se preserva este costume: "toiditos" estão convidados para compartilhar substâncias nas festas, diferentemente de outros pueblos da região onde pessoas desconhecidas são excluídas, principalmente aquelas da cidade grande, onde não se dá importância para o outro (desconhecido), onde mesmo em caso de necessidade "quien te vá a invitar?" (com um prato de comida). Nota-se uma ênfase numa perspectiva inclusiva, segundo a qual todos estão incluídos sempre; sendo assim, recusar ou não receber significa excluir-se, um movimento contrário ao movimento predominantemente desejado. Isso nos remete à perspectiva que se tem do outro nos Andes, pois uma mesma pessoa ou grupo pode ser vista ora como "nós", ora como "outro(s)". Esse pertencimento circunstancial e relativo da pessoa, expressa a necessidade e a complementaridade do outro, ver Ortiz (1993).

A penalidade máxima da comunidade é um bom exemplo do potencial transformador em "de dentro" e "de for": aquele que cometer uma falta considerada gravíssima receberá uma sanção proporcional: "Deixa de ser comunero. Com isso, perde todos os seus direitos, não pode regar... perde tudo!". Para ser um comunero é preciso cadastrarse na Directiva Comunal, e, para isso, é preciso ter vivido por dois anos 
na comunidade: "Todo habitante é comunero para nós. Dois anos vivendo aqui, você se cadastra e já é comunera!", disse-me o presidente da comunidade. O direito de cadastrar-se e tornar-se um membro da comunidade é conquistado depois de se viver por no mínimo dois anos sobre o mesmo território, sob o mesmo céu, compartilhando a mesma água, alimentando-se dos frutos que essa terra dá. Primeiro, tornar-se parte da comunidade de fato, depois de direito, status que formaliza os deveres para com a comunidade. Esse movimento de familiarização - que possui seu inverso, à semelhança do que Overing (2006) observa sobre a prática cotidiana de "fazer familiar" entre os Piaroa na Amazônia - possibilita que quase todos, segundo tais condições, possam (des) tornar-se comunero ${ }^{13}$.

Em Andamarca, o ato de dar e receber alimentos, inserindo-se no fluxo das trocas entre os locais, aponta para dois princípios centrais que podem dizer muito sobre dois tipos de pessoas: o "yarqay" (hambriento/ambicioso) e o "tacaño", por vezes associados a qualificativos como "buena" e "mala" pessoa. Dar e compartilhar são atitudes sempre positivas, visto que a reciprocidade, o ayni em seu sentido mais amplo, é um princípio central nas sociedades andinas. Exercer o movimento contrário, ou seja, não dar, reter, acumular, guardar para si, é negativo. A avareza, assim como a ambição e a cobiça, é algo muito mal visto. Ossio (2007, p. 46) faz uma referência à avareza e ao incesto: "[...] são suscetíveis de se condenar, isto é, de andar como almas errantes que devoram seres viventes, dois tipos de pecadores: os que cometem incestos e os que são avaros". O pecado de ambos é “[...] colocar freio nos intercâmbios recíprocos. O primeiro não permite ampliar o círculo das uniões matrimoniais, e o segundo interrompe a circulação dos bens". Esses seres devoradores com um apetite infinito, os quais aparecem com recorrência na literatura sobre os Andes, como os pishtacos ou kharisiris (Wachtel, 1996; Spedding, 2011), o "feto agressivo" (Platt, 2001), e outros tipos de "animal-espíritu" (Coconier, 2012) com características canibais - que extraem substâncias vitais dos humanos como sangue e gordura -, somente tomam, recebem e jamais devolvem, contrariando o fluxo ideal das coisas do universo e a ordem/ritmo ideal das prestações, residindo aí seu perigo. São seres 
que somente acumulam, sem nunca dar ou distribuir, contrariando o princípio da reciprocidade entre os diversos seres do universo.

Assim, é preciso enfatizar a importância do caráter redistributivo das festas, bem como do sistema de "cargos". Esse consiste num rodízio de "cargontes", ou anfitriões, que assumem o compromisso de dar uma festa para toda comunidade, com comida, bebida e música para todos. Há os cargos voluntários, no caso das festas religiosas, e os cargos obrigatórios, como os da Festa da Água, pois todo comunero, assim como o direito de usar água para irrigar, tem também o dever de retribuir à comunidade assumindo o compromisso de ser anfitrião. Nas festas não há apenas um cargo, mas um conjunto deles, havendo uma hierarquia. Jovens recém-casados, por exemplo, nunca serão responsáveis pelo cargo máximo, mas por um cargo proporcional à posição em que se encontram no momento. Há uma gradação de cargos por meio da qual se percebe uma lógica que leva em conta vários momentos da vida dos andamarquinos: desde os solteiros e recém-casados, a quem corresponde os cargos menores, até os casais que já alcançaram suficientes condições (idade madura, bens, filhos adultos, já passou cargos menores), os aspirantes a assumir o cargo máximo. Na Festa da Água, o cargo que ocupa o topo da hierarquia é o de "mayor de danzantes", anfitrião responsável pelos "danzantes de tijeras", a principal atração da festa ${ }^{14}$. Essa é uma obrigação exigida àqueles que usam mais água para regar e, de acordo com um princípio de proporcionalidade, devem retribuir/devolver mais, através do cargo mais importante e mais caro.

Aquele que reúne todas as condições e ainda não assumiu um cargo correspondente tem chance de ser apontado diante de todos nas assembleias, espaços em que se definem muitos assuntos referentes à vida coletiva: "Él tiene que pasar [cargo]!". Caso a resposta dessa pessoa seja negativa, terá de ter uma boa justificativa: doença grave na família, morte recente da esposa/filho/pais, devendo também realizar uma previsão do cumprimento do seu compromisso. Trata-se de um constante concentrar e distribuir ao longo da vida; quando se alcança mais um nível da hierarquia social, considera-se que já se está pronto para assumir outra obrigação, até alcançar o topo dos cargos. Muitas vezes, mesmo que o candidato para passar um cargo não tenha recursos 
materiais para isso, apesar de ter idade, pode ter uma rede de familiares que o ajudarão a cumprir tal responsabilidade: compadres, padrinhos, pais, irmãos, primos, tios. Os parentes lhe darão em ayni - palavra quechua que significa retribuição, reciprocidade - ou seja, ajudarão esperando receber a retribuição no futuro, quando cada um deles tiver uma obrigação semelhante.

Conforme alguns andamarquinos, o lado negativo do sistema de cargos é que ele "no te deja progresar"; tudo que foi economizado durante anos terá de ser gasto com a festa. Nesse sentido, é um mecanismo anticoncentração. Por outro lado, quando alguém se compromete a ser anfitrião, além de "cumplir" com a obrigação, questão de honra e reputação, pode também ganhar muito prestígio entre os comuneros. Tudo depende de quão bom anfitrião será, se a festa que oferecer for considerada pelos demais como uma boa festa, com bons músicos e dançarinos, fartura de comida e bebida. A soma dos requisitos indispensáveis indicará se tal pessoa é tacaña, categoria indesejada, ou se "passou bem" seu cargo.

\section{Rotação e Alternância}

Voltando à importância da água para os andamarquinos, realçada desde o mito de origem de Andamarca até os dias de hoje com a celebração anual da Festa da Água, vale ressaltar que a irrigação apresenta uma ordem específica, de acordo com a qual a água passa por todos os andenes, de baixo para cima. O dono do andén "recebe" a água e após utilizar o que tem direito deve "passar" para o próximo, e assim sucessivamente. De forma geral, o movimento e a ordem, de cima para baixo, ou o contrário; e do maior ao menor, ou o inverso, remete a uma disposição que tem como princípio o escalonamento. Arnold (1998, p. 198) mostra que os contos narrados também possuem uma estrutura que ordena as aves, de maior a menor em tamanho, e de maior a menor na hierarquia, e, ainda, de cima para baixo. Se tomarmos os andenes como uma metáfora visual local, imediatamente pode-se ver uma gradação de microclimas, de altura, semelhante à distribuição de cores de uma manta. Segundo a explicação de uma amiga, pude notar que também se usa "alto" e "baixo" para se referir à 
intensidade das cores. A escala das cores parte, por exemplo, do "verde bajito", mais suave ou fraco, até o mais intenso, ou "alto", um dégradé.

Isso tudo ressalta a importância das pequenas variações, sendo que o movimento de rotação acompanha a lógica do escalonamento, através do qual se pode subir um pouco mais, como no caso dos cargos; onde a ênfase nunca recai sobre um apenas, mas vários, porém, em graus diferentes e onde a alternância predomina sobre a estagnação. O cargo é proporcional à posição em que a pessoa/casal se encontra no momento. Portanto, os cargos são como degraus a serem escalados, até que um dia se chegará ao topo. O sistema de cargos se caracteriza por ser um rodízio, cujo princípio central é ocupar uma vez cada posição. O curto período de permanência de um cargo (festivo ou civil) permite uma rotação intensa de andamarquinos em sua execução, fazendo com que ninguém se acostume a tal posição - mesmo os cargos civis possuem um curto período de duração (de um a três anos, no máximo) - privilegiando assim a alternância.

Diante disso, nota-se que em diversas situações a ênfase recai sobre a rotação/alternância, e não na estagnação/retenção. Em determinados momentos concentração e acumulação devem acontecer, mas respondendo a certos limites, jamais desmedidamente. Algo paralelo se passa na irrigação de andenes, que devem ser inundados apenas o suficiente para que os cultivos germinem, do contrário correm o risco de desabar. Da mesma forma que um casal deve acumular bens ao longo da vida para deixar herança a seus filhos, mas nunca a ponto de se converterem em pessoas ambiciosas e egoístas. Com isso, um importante aspecto a ser ressaltado em relação ao ayni/reciprocidade é seu caráter alternante, localmente definido por alguns andamarquinos como "hoy por ti, mañana por mi", ou seja, um revezamento de prestações.

\section{Notas:}

1 Uma versão preliminar deste trabalho foi apresentada na X Reunião de Antropologia do Mercosul em 2013, na cidade de Córdoba (Argentina), no GT 21 "Entre Andes e Amazônia: Transformações de matérias, substâncias e corpos". Agradeço a Francisco Pazzarelli e a Denise Arnold pelos comentários na ocasião, os quais me ajudaram a aprimorar esta versão; e também à leitura atenta de Rogério Azize e ao apoio técnico de Marcelo Mello. 
2 Doutora em Antropologia Social pelo PPGAS-MN/UFRJ, integrante do Núcleo de Antropologia do Trabalho, Estudos Biográficos e de Trajetórias (NuAT), com sede no Museu Nacional/UFRJ.

3 O Valle de Sondondo é formado pelos distritos de Chipao, Cabana Sur, Aucará e Santa Ana de Huaycahuacho.

4 Conforme Kendall e Rodríguez (2009, p. 168), ao redor de Andamarca há entre 1.000 e 2.000 hectares de andenes cultivados, o que é um “[...] magnífico exemplo e resultado da responsabilidade e dedicação organizativa da comunidade na sua manutenção desde a época pré-hispânica, de sua infra-estrutura de irrigação, muros e plataformas de cultivo". Além de ser uma das poucas comunidades peruanas que ainda conserva a maior parte de seu sistema de andenería, os autores apontam para algumas inovações apropriadas pelos andamarquinos nos últimos 30 anos, como, por exemplo, a criação de acessos convenientes para bois (usados para arar), a rotação de cultivos e acesso entre os andenes.

5 Os distritos são as menores unidades político-administrativas do Peru, cujo governo está a cargo de uma municipalidade distrital, encabeçada por um prefeito eleito a cada quatro anos por meio de eleições diretas.

6 Nos anos de 1970, a população de cada anexo superava a centena (Ossio, 1992). Nos últimos anos, o número de moradores dos anexos diminui radicalmente.

7 Os dados apresentados neste artigo são fruto de pesquisa etnográfica realizada entre 2009 e 2011 , com duração de aproximadamente 15 meses.

8 Mayo Sahua, Mayo Huaylla, Mayo Huacca e Mayo Anta originaram-se na lagoa de Yaurihuiri, rumando ao norte na busca de terras férteis, e, onde terminassem suas sandálias de ouro, fundariam uma cidade. O primeiro caiu acidentalmente em um barranco, convertendo-se na lagoa que se conhece hoje com o nome de Sahuaccocha. O segundo, sedento, viu um manancial e, quando estava tomando água, ficou encantado, pois a fonte era uma mulher e estava rodeada pela grama Huaylla, por isso o nome Huayllahuarmi. O terceiro perdeu uma de suas sandálias no caminho, e, ao voltar para buscá-la, viu uma linda mulher. Ao tentar abraçá-la, converteu-se em pedra. Assim surgiu o nome Huaccaracca. O último, Anta, chorou muito pelos seus irmãos. As lágrimas do olho direito deram origem então ao rio Negromayo, e as do olho esquerdo, ao rio Vizca. Esse Mayo decide fundar sua morada no lugar onde suas lágrimas ficassem empoçadas. De tanto que chorou, navega em suas lágrimas até chegar a seu destino, dá voltas ao redor de um morro à margem da única ilha existente e assim funda a cidade de Antamarca. Daí o sufixo "marca", que designa a parte mais alta de uma casa.

9 O que Ortiz também chama de "mediador" e de "punto medio" quando analisa diversos mitos andinos, encontrando personagens que estão nessa posição de "chaupi mediador" entre dois extremos (1980, p. 60). Um deles é o zorro, um personagem que transita entre dois mundos, ver também Arnold (1998).

${ }^{10}$ Os andamarquinos contam que este último traço diferenciador foi crucial para o surgimento e a consolidação das ideias defendidas pelo Sendero Luminoso em Andamarca no início dos anos de 1980. Devido aos abusos cometidos pelos mistis, alguns foram mortos nessa época, evento que acarretou o êxodo de grande parte da população de Andamarca para a costa, permanecendo no pueblo durante alguns anos apenas os mais velhos.

${ }^{11}$ Expressão em espanhol que denota certo carinho, amabilidade. Para os homens utiliza-se papi. 
12 O parentesco por juramento, segundo me explicou um amigo, ocorre entre pessoas muito próximas, "que se congenian" ["que se compreendem"], "que se llevan muy bien", não ligadas por laços de sangue ou afinidade, que fazem um "juramento" de parentesco, e, assim, passam a ser parentes. Dessa forma, um rapaz jovem e um senhor podem fazer juramento de pai e filho, ou uma senhora e uma moça, de mãe e filha - ou ainda no caso de sexos cruzados, de mãe e filho ou pai e filha. Duas pessoas com idades aproximadas, geralmente, fazem juramento de irmãos. Para que tenha eficácia, é preciso que esse juramento seja feito na presença de um "anciano", ou na presença de um padre. Esse é um parentesco que gera obrigações para ambas as partes. Os irmãos de um filho de juramento do pai de uma pessoa tornam-se seus "irmãos políticos", ou seja, irmãos por afinidade e não consanguíneos.

13 Os sallqas parecem ser o único tipo de gente que não se incorpora na comunidade da mesma forma, senão que possui sua própria associação, não se cadastrando na Directiva. Passam a fazer parte da comunidade, mas não da mesma forma que outros forasteiros.

14 A "danza de tijeras" é originária dos departamentos de Ayacucho, Huancavelica, Apurímac e norte de Arequipa, na serra sul dos Andes Centrais do Peru. O "danzante" ou "danzaq", em quechua, desempenha sua performance sozinho ao som de violino e harpa, manuseando com apenas uma das mãos uma tesoura, considerada um instrumento musical. Em Andamarca a dança de tesouras tem um importante lugar na Festa da Água, pois é um ritual propiciatório para o bom desenvolvimento do ano agrícola. (Arce Sotelo, 2006)

\section{Referências}

ALFARO FREIRE, Maria José. Rumi Llacta. Turismo, tradição e política em Sibayo (Peru). Tese de Doutorado. Programa de Pós-Graduação em Antropologia Social do Museu Nacional/UFRJ, 2011.

ARCE SOTELO, Manuel. La danza de tijeras y el violín de Lucanas. Lima: IFEA; PUC/Instituto de Etnomusicología, 2006.

ARNOLD, Denise; YAPITA, Juan de Dios. (Compiladores). Madre Melliza y sus Crias Ispall Mama Wawampi. Antología de la papa. La Paz: Hisbol Ediciones - ILCA, 1996.

. Hacia un orden andino de las cosas. Tres pistas de los Andes

meridionales. La Paz: Hisbol Ediciones - ILCA, 1998.

BELAUNDE, Luisa Elvira. Viviendo bien: género y fertilidad entre los AiroPai de la Amazonía peruana. Lima: CAAAP/BCRP, 2001.

COCONIER, Gala. “iQolaq Sequi'aq!" (“iVamos a comer!”). Identidad, comensalidad y género en la alimentación de los Qom (Toba) del CentroEste de Formosa. In: BABOT et al. (Ed.). Las manos en la masa: Arqueologías, Antropologías e Historias de la Alimentación en Suramérica. Córdoba: Universidad Nacional de Córdoba, Facultad de Filosofía y Humanidades; Museo de Antropología UNC - Instituto Superior de Estudios Sociales UNT, 2012. 
ISBELL, Billie Jean. Para defendernos: ecología y ritual en un pueblo andino. Cuzco: Centro de Estudios Regionales Andinos Bartolomé de Las Casas, 2005. KENDALL, Ann; RODRÍGUEZ, Abelardo. Desarrollo y perspectivas de los sistemas de andenería en los Andes Centrales del Peru. Cuzco: Centro de Estudios Regionales Andinos Bartolomé de Las Casas; Instituto Francés de Estudios Andinos, 2009.

ORTIZ RESCANIERE, Alejandro. Huarochirí, 400 años después. Lima: Pontifícia Universidad Católica del Perú, 1980.

. La pareja y el mito: estudio sobre las concepciones de la persona y de la pareja en los Andes. Lima: Pontifícia Universidad Católica del Perú, 1993. OSSIO, Juan. Los mitos de origen en la Comunidad de Andamarca (Ayacucho-Perú). Allpanchis, Perú, v. 10, 2. ed., p. 105-113, 1981.

. Parentesco, reciprocidad y jerarquia en los Andes: una aproximación a la organización social de la comunidad de Andamarca. Lima: Pontificia Universidad Católica del Perú; Fondo Editorial, 1992.

. Andinidad. In: ABAD CASAL, Lorenzo [et al.]. Del Meditárraneo a los Andes. Alicante: Caja Mediterráneo, 2007.

. En busca del orden perdido: la idea de la Historia en Felipe Guaman Poma de Ayala. Lima: Fondo Editorial de la Pontificia Universidad Católica del Perú, 2008.

OVERING, Joanna. Elogio do cotidiano: a confiança e a arte da vida social em uma comunidade amazônica. Mana. Estudos de Antropologia Social, Rio de Janeiro v. 5, n. 1, p. 81-107, 1999.

. What's the difference between a peace corps worker and an anthropologist? In: POSEY, Darrell Addison; BALICK, Michael. Human Impacts on Amazonia: the role of Traditional Ecological Knowledge in Conservation and Development. New York: Columbia University Press, 2006.

PALOMINO, Salvador. El sistema de oposiciones de la comunidad de Sarhua. Lima: Pueblo Indio, 1984.

PLATT, Tristan. El feto agresivo. Parto, formación de la persona y mito-historia en los Andes. Anuário de Estudios Americanos. Tomo LVIII, 2, 2001.

SPEDDING, Alison. Sueños, kharisiris y curanderos: dinámicas sociales de las creencias en los Andes contemporáneos. La Paz: Editorial Mama Huaco, 2011. WACHTEL, Nathan. Deuses e Vampiros: de volta a chipaya. São Paulo: EdUSP, 1996.

Recebido em 28/08/2013

Aceito em 21/11/2013 